\title{
Outcomes of the BOSS Classroom Management Program Among Adults With Intellectual Disabilities
}

\author{
Mick Needham \\ Walden University \\ Peter Ross \\ Walden University \\ Karen Slonski \\ Walden University \\ Steven Wells \\ Walden University \\ Andrew W. Wood \\ Department of Intellectual and Developmental Disabilities, Knoxville, Tennessee
}

\begin{abstract}
There is a current and growing need for evidence-based practices aimed at improving the social skills of adults with intellectual disabilities (ID). Despite an abundance of research on strategies to improve the social skills of young children with ID, there is limited research on interventions aimed at improving prosocial behaviors of adults with ID. A behavioral skills training approach was used to teach frontline, direct support professionals (DSPs) to implement a classroom management strategy called the Behavioral Opportunities for Social Skills (BOSS) program with adults with ID who lived in the community. The results showed that DSPs' delivery of behavior-specific praise statements increased after they received training in the BOSS program. Increases in the prosocial behaviors of the adults with ID were also reported after the DSPs were trained. Social validity measures indicated that DSPs liked using the BOSS program, it was easy to implement, and the program was effective. The results of this study suggest that evidence-based social skills interventions developed for children and adolescents, including classroom management strategies, can be effective in improving prosocial behaviors of adults with ID with minimal adaptions.
\end{abstract}

Keywords: applied behavior analysis, classroom management, BOSS teaching program, adults with intellectual disabilities, social skills

The authors declare that they have no conflict of interest. All procedures performed in studies involving human participants were in accordance with the ethical standards of the institutional and/or national research committee and with the 1964 Helsinki declaration and its later amendments or comparable ethical standards. This investigation was reviewed and approved by the University Institutional Review Board. This investigation was also reviewed and approved by the Tennessee Regional Human Rights Committee. The Tennessee Regional Human Rights Committee reviewed the risks and benefits of conducting the study with a sample of Department of Intellectual and Developmental Disability service recipients, the informed consent process and forms, and the study intervention and design.

Please address queries to: Mick Needham, Walden University. Email: mick.needham@waldenu.edu 


\section{Introduction}

Individuals diagnosed with intellectual disabilities (ID) commonly have significant deficits in their social skills repertoires (Burke, Wagner, Marolda, Quintana, \& Maddux, 2017; Walton \& Ingersoll, 2013). Deficits in social skills of people with ID have been associated with maladaptive behaviors, including aggressive behavior toward others, destructive behaviors, self-injury, and pica (Delgado, Gonzalez-Gordon, Aragón, \& Navarro, 2017; Lloyd \& Kennedy, 2014; Matson \& Adams, 2014; Matson, Hattier, \& Turygin, 2012). Research has shown that social skills deficits and maladaptive behaviors have also been associated with a reduced quality of life due to restricted community participation (Kearney \& Healy, 2011; Koegel, Ashbaugh, Koegel, Detar, \& Regester, 2013) and difficulties in maintaining employment (Heyman, Stokes, \& Siperstein, 2016; Walsh, Lydon, \& Healy, 2014).

Researchers have acknowledged that inappropriate social behavior and social skills deficits of children with ID do not improve with age and tend to persist into adulthood (Gantman, Kapp, Orenski, \& Laugeson, 2012; Hotton \& Coles, 2016; Turcotte, Mathew, Shea, Brusilovskiy, \& Nonnemacher, 2016). Additionally, researchers have suggested that social skills deficits may exacerbate or lead to other challenging behavior and are unlikely to change without effective strategies for improvement (Delgado et al., 2017; Matson \& Adams, 2014). Although there is an abundance of research on social skills interventions for young children with ID, there is limited research on interventions aimed at improving the social skills of adults with ID (Dudley, Klinger, Meyer, Powell, \& Klinger, 2019; Koegel et al., 2013; Matson, Cervantes, \& Peters, 2016; Walton \& Ingersoll, 2013). A review of evidence-based social skills interventions with individuals with ID showed that a significant portion of studies included participants who were 12 years of age or younger (Wong et al., 2015). The review by Wong et al. also reported that the number of published studies decreased as the age categories of the participants increased.

There is a current and growing need for the development and expansion of evidence-based practices to improve the social skills of adults with ID (Bishop-Fitzpatrick, Minshew, \& Eack, 2014; Cox, Dube, \& Temple, 2014; Gerhardt \& Lainer, 2011). Adults with ID continue to transition from living in state-run institutions and similar settings to community-based supports as a part of the deinstitutionalization movement (Lerner \& Pollack, 2015). There has also been a substantial increase in the prevalence of autism spectrum disorder diagnoses in the past 20 years (Dudley et al., 2019; Ratto \& Mesibov, 2015). Many individuals who were diagnosed at the onset of the spike in prevalence rates are now young adults and are transitioning from living at home with their families to the regular community.

Although there are significantly fewer studies on social skills interventions with adults with ID, the literature base on social skills interventions with children has been beneficial for the generalization of the interventions across age groups (Ashman, Banks, Philip, Walley, \& Stanfield, 2017; Walton \& Ingersoll, 2013). The current literature on social skills interventions for children with ID indicates that some of the most effective interventions include components of applied behavior analysis (ABA; Axelrod, McElrath, \& Wine, 2012; Cowan, Abel, \& Candel, 2017; Ke, Whalon, \& Yun, 2018; Matson et al., 2012). Recently, researchers have demonstrated that evidence-based social skills interventions developed for children and adolescents with ID can be successfully implemented with adults with ID (Ashman et al., 2018; Laugeson et al., 2015). The interventions that have been successfully adapted and implemented with adults with ID also include clear components of ABA, including modeling, positive reinforcement, direct feedback, and behavioral rehearsal (Laugeson \& Ellingsen, 2014).

In the school system, behavioral-analytic social skills interventions have been used as an effective form of classroom management (Floress, Beschta, Meyer, \& Reinke, 2017; Jenkins, Floress, \& Reinke, 2015). The Behavioral Opportunities for Social Skills (BOSS) program is a classroom 
management strategy that incorporates the principles of ABA, including modeling, differential reinforcement of prosocial behaviors, and extinction of inappropriate social behaviors (Ross, 2015). The BOSS program has been shown to be an effective strategy for increasing positive peer interactions and prosocial behaviors of students in the classroom, which are important outcomes for increasing community integration for adults with ID (Long, 2016). Thus, the BOSS program represents a promising social skills intervention to be expanded to the adult ID population, which was the focus of this investigation.

The BOSS program provides teachers with a highly structured, step-by-step curriculum to follow to avoid the common pitfalls associated with traditional classroom management techniques. The BOSS program encourages teachers to abandon reactive and punishment-oriented approaches and to learn new behaviors themselves (Ross, 2015). In the classroom setting, negative teacher attention in the form of repeated reprimands may function as a positive reinforcer for students (Mrachko, Kostewicz, \& Martin, 2017). Reactive strategies may inadvertently increase challenging behavior and can also produce unwanted side effects. The BOSS program emphasizes the proactive, contingent delivery of behavior-specific praise statements (BSPSs), which has been identified as a standalone evidencebased practice for effective classroom management (Simonsen, Fairbanks, Briesch, Myers, \& Sugai, 2008; Simonsen, et al., 2017).

Direct support professionals (DSPs) who provide daily support to adults with ID in the community face similar behavioral challenges commonly encountered by teachers in the classroom. However, turnover rates for DSPs have been reported to be substantially higher than other industries at approximately 50\% (Friedman, 2018; Gerhardt \& Lainer, 2011). Inadequate training for DSPs and behavioral challenges of supported persons have frequently been cited as reasons for the high turnover rates (Bogenschutz, Nord, \& Hewitt, 2015; Reinke et al., 2013). Often, staff trainings include classroom-oriented lectures rather than hands-on practice and skill development. In the absence of effective training, DSPs are likely to rely upon their existing repertoires, which tend to include traditional, idiosyncratic, and reactive strategies (Gerhardt \& Lainer, 2011; Ross \& Sliger, 2015). For human services agencies to avoid costly turnover rates and to retain their frontline workforce, DSPs need effective training in the application of evidence-based, behavior-analytic practices.

The purpose of this investigation was to teach DSPs to implement the BOSS classroom management program with adults with ID in the community using a behavioral skills training approach. After DSPs were trained in the BOSS program, we evaluated changes in the frequency of BSPSs delivered by DSPs, differences in the frequency of prosocial behaviors of adults with ID, and changes in the frequency of challenging behaviors exhibited by the adults with ID. Social validity measures were also collected to examine the DSPs' practical experiences with using the BOSS program. Practical considerations for training DSPs to use the BOSS program with adults with ID in the community setting are provided for education professionals, behavior analysts, and community agency personnel involved in staff training.

\section{Method}

\section{Setting and Participants}

The participants were recruited from a community-based provider agency that participated in the Tennessee Department of Intellectual and Developmental Disabilities (DIDD) network of programs for adults with ID. Informed consent (or assent, in the case a person's legal representative provided informed consent) was obtained from all individual participants included in the study. Three DSPs who worked as frontline support staff with adults with ID received the behavioral skills training on the components of the BOSS program. The three DSPs, each of whom worked with a different adult 
with ID, all held a high school diploma or equivalent. One of the DSPs (DSP3) was a senior undergraduate student but had not graduated. Two of the DSPs were female (DSP2 and DSP3), and one was male (DSP1). The DSPs ranged in age from 22 to 45 years old and did not have prior experience with the BOSS program. The DSPs were selected because they did not have prior experience with the BOSS program and they each supported an adult with ID who was not actively receiving formal ABA services.

The three adults with ID received funding from the Tennessee DIDD, which required a diagnosis of at least one ID prior to the age of 18. Person Supported (PS) 1 was a 27-year-old male diagnosed with fetal alcohol syndrome, bipolar disorder, depression, attention-deficit/hyperactivity disorder, psychotic schizophrenia, pyromania, insomnia, and skeletal dysplasia. PS2 was a 27-year-old female diagnosed with ID, mood disorder, anxiety disorder, and seizure disorder. PS3 was a 21-year-old male diagnosed with ID, obsessive-compulsive disorder, anxiety disorder, and hypothyroidism. A review of archival records indicated that all three adults with ID had histories of behavioral challenges and had received formal ABA services in the past.

\section{Behavioral Skills Training and the BOSS Program}

Behavioral skills training has been shown to be an effective approach for training teachers, caregivers, and human services staff to implement a variety of behavior change procedures (DiGennaro Reed, Blackman, Erath, Brand, \& Novak, 2018; Hassan et al., 2018; Parsons, Rollyson, \& Reid, 2012). Parsons et al. described evidence-based staff training as a sequence of six steps: “1) describe the target skill, 2) provide a succinct, written description of the skill, 3) demonstrate the target skill, 4) require practice of the target skill, 5) provide feedback during practice, 6) repeat steps 4 and 5 to mastery" (p. 3). The training of DSPs in the BOSS program followed the behavioral skills training sequence and the practical recommendations for efficient community-based training sessions.

Much like the teachers who participated in prior applications of the BOSS program in the school setting, DSPs were the primary implementers of the program in this study (see Long, 2016; Ross, 2015). Step 1 of the BOSS program included training DSPs how to ignore nuisance behavior, identify desirable behavior, and deliver BSPSs contingent upon the display of prosocial behaviors by the adults with ID. Step 1 of the BOSS program is defined by Ross as follows:

Teachers state that they will be watching for prosocial or "cooperative and polite behaviors" (CPBs) (teachers spend time helping students define and demonstrate both "cooperation and politeness") and frequently compliment students during the day when they demonstrate cooperative and polite behavior. At the same time, teachers ignore nuisance behaviors. If the teacher needs to redirect a student, she either points out those students who are displaying CPBs, or politely asks the student in question to "show me some CPBs" (p. 115).

For the purposes of this study, the BOSS program terms of teacher and student were replaced with direct support professional and person, individual, or adult with ID. The specific instructions for implementing the BOSS program were reviewed during each training session. Ross (2015) delineated the following instructions for implementing the BOSS program, which were the basis for training DSPs in this study:

1. Regularly ignore nuisance behavior;

2. Resist being reactive to inappropriate behavior;

3. Point out the behaviors you want [what Partin et al. (2010) refer to as "opportunities to respond." It is very important that teachers take opportunities to point out desirable behaviors as often as possible. This will help insure that \#5 below is maintained]; 
4. Punctuate [i.e., make a "big deal" or celebrate] especially desirable behaviors when they occur;

5. Make sure that the BOSS language is $25 \%$ of your overall communication with students [i.e., you must continue to talk about desirable behavior, reinforce desirable behavior, and model desirable behavior throughout the day]. (p. 114)

\section{Behavioral Definitions and Data Collection}

Frequency data were collected by DSPs on the number of prosocial behaviors they observed the adults with ID display and the number of BSPSs they delivered to supported persons during baseline and intervention phases. The DSPs also collected frequency data on the number of challenging behaviors they observed the adults with ID display. In a recent application of the BOSS program, Long (2016, p. 193) categorized and defined prosocial behavior as follows:

1. Proximity: Being near a peer appropriately

2. Cooperating: Verbally or nonverbally

3. Friendliness and affection: Amiable words and actions

4. Humor: Laughing, playing, or joking appropriately

5. Comments: Positive or affirming

6. Talking: Engaged in appropriate conversation

7. Helping: Assisting a peer with a task verbally or nonverbally

8. Sharing: Sharing materials or ideas

9. Turn taking: Waiting for turn

10. Empathy/Sympathy/Caregiving: Expressing or showing concern verbally or nonverbally.

For the purpose of this investigation, the operational definition of prosocial behavior was adapted from the Long study with slight modifications to align more appropriately with adults living in the community. For example, the term peer was replaced with others to use more adult-oriented language. A BSPS was defined as a comment that specifically indicates desirable behavior or something a person did well (Floress et al., 2017; Jenkins et al., 2015).

The frequency data on challenging behaviors were collected by DSPs as mandated by Tennessee DIDD and the community provider agency where the staff members were employed. Tennessee DIDD categorizes specific types of challenging behaviors as reportable behavioral-psychiatric incidents and requires timely submission of these reports to the state. According to the DIDD (2014, pp. 99-102) Provider Manual, reportable behavioral-psychiatric incidents can include

1. Sexual aggression;

2. Missing person longer than 15 min;

3. Criminal conduct;

4. Property destruction greater than $\$ 100$;

5. Serious injury to person supported;

6. Serious injury to another person as a result of a behavioral incident by a person supported;

7. Psychiatric/Medical hospitalization-any hospital admission whether planned or unplanned; routine age-related testing is not considered reportable;

8. Manual or mechanical restraints;

9. Protective equipment;

10. Mental Health Mobile Crisis Team-response by an independent mental health agency team to assess behavioral-psychiatric crises;

11. Emergency psychotropic medication;

12. Police involvement;

13. Incarceration. 
The provider agency also collected nonreportable behavior incidents, which included instances of physical aggression that did not result in serious injury, destruction of property valuing less than $\$ 100$, and other challenging behaviors that did not meet the DIDD reportable incident definition.

\section{Experimental Conditions}

\section{Experimental Design}

A multiple-baseline design across participants was used to evaluate changes in DSPs' delivery of BSPSs and changes in prosocial and challenging behaviors of the adults with ID.

\section{Baseline}

The baseline or pretraining condition lasted a minimum of 2 weeks but varied in duration due to the staggered initiation of trainings in the BOSS program. Throughout each of their work shifts, DSPs collected frequency data on their delivery of BSPSs and the prosocial and challenging behaviors of the adults with ID they supported. Initial trainings in the BOSS program were implemented with each DSP, each of whom worked with a different adult with ID, in a staggered and sequential manner as stable baseline and intervention data were collected over time. Each of the adults with ID lived in a different community-based supported living residence. The DSPs continued to collect the frequency data throughout the intervention phase, which included weekly training and feedback sessions.

\section{Training and Feedback}

Behavioral skills training sessions in the BOSS program occurred one time per week and lasted approximately 30 to 45 min each during the 6-week intervention phase. During the initial training session, DSPs received classroom-style instruction using a PowerPoint presentation on the concepts of the BOSS program, including relevant principles of ABA (i.e., positive reinforcement, differential reinforcement, extinction, etc.). The DSPs received training on the definition of BSPSs and had the opportunity to practice using BSPSs during role-play and a review of examples and nonexamples of BSPSs. The initial training session also provided DSPs with instructions for reviewing a daily guide for using the BOSS program at the start of their work shift, completing a treatment fidelity checklist at the end of each work shift, and behavioral data collection. Subsequent training and feedback sessions included on-the-job opportunities for the DSPs to role-play and practice using the BOSS program procedures with the adults with ID they supported.

During weekly training and feedback sessions, the trainer observed the DSPs working with the adults with ID and provided BSPSs and corrective feedback on their use of the BOSS program procedures. The trainer modeled the response-contingent delivery of BSPSs and the ignoring of nuisance behaviors. The nuisance behaviors were defined as behaviors that were considered annoying to the DSPs and others, but were not causing serious problems and did not meet the operational definitions for reportable or nonreportable challenging behavior incidents. The DSPs were also provided visual feedback on the frequency of their delivery of BSPSs per work shift using line graphs.

\section{Implementation Fidelity}

The trainer collected implementation fidelity data on the DSPs' application of the BOSS program using a checklist during each of training and feedback sessions. The treatment fidelity checklist included each of the steps for implementing the BOSS program and was identical to the checklist DSPs were trained to complete at the end of their work shifts. The trainer completed a checklist for each DSP during each of the training and feedback sessions while observing the DSPs using the BOSS program. Each of the DSPs completed 100\% of their daily treatment fidelity checklists and reported having implemented the BOSS program consistently and accurately as indicated by ratings 
of $100 \%$ fidelity on all checklists. The DSPs were also observed to be following the components of the BOSS program with $100 \%$ accuracy during the training and feedback sessions.

\section{Interobserver Agreement}

Procedures for collecting interobserver agreement data during the baseline and intervention phases, as well as during treatment fidelity checks were initially included in this investigation via contributions of a research assistant. However, the Institutional Review Board that provided oversight of the investigation did not allow assistants to collect research data. The planned evaluations of treatment fidelity during the intervention phase were still conducted, but without reliability measures that necessitate a second trained observer. Thus, the absence of interobserver agreement measures, which require simultaneous observations by two independent and trained observers, represents a limitation of this investigation.

\section{Social Validity}

An eight-question social validity survey was distributed to each DSP at the end of training and feedback phase. Each DSP completed the survey independently to avoid introducing researcher bias to their responses. The survey included open-ended questions regarding the DSPs' experiences in using the BOSS program.

\section{Results}

Training in the BOSS program was initiated at staggered time points across three DSPs, each of whom supported a different adult with ID. Each of the adults with ID lived in separate homes, and one of the adults with ID lived in a completely different city and county approximately $30 \mathrm{mi}$. from the other participants. As indicated in Figure 1, each DSP substantially increased his or her delivery of BSPSs during the training and feedback condition compared to baseline. Figure 1 also shows discernable increases in the rates of prosocial behaviors for each of the adults with ID during the training and feedback condition. Although the DSPs typically worked 8-hr shifts, there were some variations in their work shift durations (i.e., 6-12 hr). The DSPs' delivery of BSPSs and prosocial behaviors of the adults with ID are reported as rates to allow for equal comparisons across the work shift durations.

The baseline rates of PS1's prosocial behaviors and DSP1's delivery of BSPSs show a relatively stable trend. Immediately following the initial training on the BOSS program (indicated by the dashed vertical phase line in Figure 1), there was an increase in DSP1's delivery of BSPSs and an increase in PS1's prosocial behaviors. The rate of DSP1's delivery of BSPSs and the rate of prosocial behaviors of PS1 showed a steep increase during the training and feedback phase. At the end of the intervention phase, BSPSs reached 12.37 instances per hour and prosocial behaviors reached 12 instances per hour, which more than doubled the baseline median for each variable. The intervention phase for DSP1 was terminated earlier than planned because DSP1 was transferred to work with another person supported within the agency.

The baseline rates of prosocial behaviors of PS2 and PS3 and the delivery of BSPSs by DSP2 and DSP3 showed relatively stable trends. Immediately following the initial training on the BOSS program, there was a discernable increase in DSP2's delivery of BSPSs and an increase in PS2's prosocial behaviors. The increase in DSP2's delivery of BSPSs and PS2's prosocial behaviors were maintained at the higher rates with moderate variability throughout the training and feedback phase. Immediately following the initial training on the BOSS program, there was a moderate increase in DSP3's delivery of BSPSs and a moderate increase in PS3's prosocial behaviors. Although the initial increase was moderate, DSP3's delivery of BSPSs and PS3's prosocial behaviors showed a discernable increasing trend throughout the training and feedback phase. 


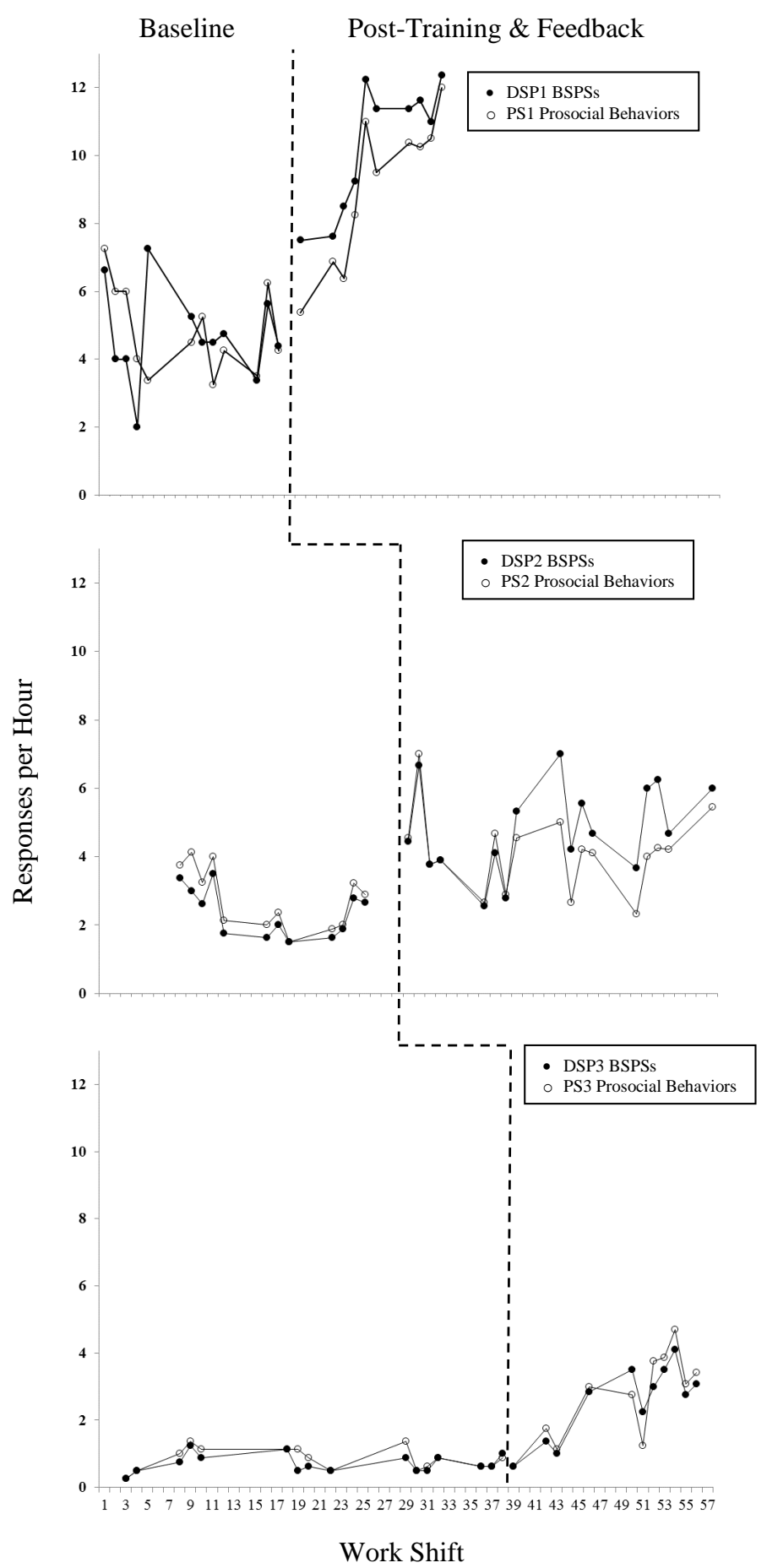

Figure 1. The Number of Behavior-Specific Praise Statements (BSPSs) Delivered by Each Direct Support Professional (DSP) and the Number of Prosocial Behaviors Displayed by Each Adult With ID per Hour During Each DSP's Work Shift Across the Baseline and Posttraining and Feedback Conditions. PS = Person Supported. 
As a supplementary analysis, the percentage of data points exceeding the median (PEM) effect size calculations were also conducted on the rates of DSPs' delivery of BSPSs and the prosocial behaviors of the adults with ID. The PEM analyses were calculated by identifying the median for each dependent variable during the baseline condition and calculating the PEM values during the intervention phase (see Cowan et al., 2017; Vannest \& Ninci, 2015). The PEM during the training and feedback phase for DSP1's delivery of BSPSs and the prosocial behaviors of PS1 were identical at $100 \%$ ( $E S=1.0$ ) for each variable. The PEM for DSP2's delivery of BSPSs was also $100 \%$ ( $E S=$ 1.0). The PEM of PS2's prosocial behaviors was $94 \%(E S=.94)$. The PEM of DSP3's delivery of BSPSs and PS3's prosocial behaviors were identical at $92 \%(E S=.92)$. Thus, large effect sizes were obtained through the PEM analyses of the rates of prosocial behaviors of all three adults with ID as well as the delivery of BSPSs by all three DSPs.

Although there were discernable increases in the DSPs' delivery of BSPSs and the prosocial behaviors of the adults with ID, there was not a sufficient number of challenging behavior incidents during the baseline or intervention phases to adequately conduct visual or effect size analyses. There were eight challenging behavior incidents across all three adults with ID during the recruitment, baseline, and intervention phases. The challenging behavior incidents are summarized in Table 1 due to the small number of incidents documented. The challenging behavior incident narratives provide insight to the types of behavioral issues DSPs face on a regular basis while working with adults with ID in the community. Although the challenging behaviors were not frequently documented, subjective review of the narratives indicate the incidents were socially significant with a high likelihood to disrupt participation in community-based activities if they were to persist. The incident narratives included in the table are verbatim of the language used by the author of the narrative with editing only to remove identifying information.

The results of the social validity survey are summarized in Table 2, which includes exact narrative statements from the DSPs on each of the survey questions regarding their experiences in using the BOSS program with the adults with ID they supported. Overall, the three DSPs reported having a positive experience with the BOSS program. All of the DSPs reported that the BOSS program was very easy to use and was effective at increasing the prosocial behaviors of the adults with ID they supported. The DSPs also stated that they were very likely to continue using the BOSS program and expressed their desire to see the program expanded to other agencies. Two of the DSPs stated that they had already expanded their use of the BOSS program to other adults with ID they supported, as well as with their own children. One DSP reported that he was so pleased with the BOSS program that he began using the program with the T-ball team he coached. 
Table 1. Challenging Behavior Incidents

\begin{tabular}{|c|c|c|}
\hline $\begin{array}{l}\text { Person } \\
\text { Supported } \\
\text { (PS) }\end{array}$ & $\begin{array}{l}\text { Type of } \\
\text { Incident }\end{array}$ & Notes \\
\hline \multirow[t]{4}{*}{ PS1 } & $\begin{array}{l}\text { Reportable } \\
\text { behavioral/ } \\
\text { psychiatric } \\
\text { incident- } \\
\text { other }\end{array}$ & $\begin{array}{l}\text { PS1 called } 911 \text { on the previous shift; officers arrived and were talking with } \\
\text { PS1. He told police that he was depressed and wanted to harm himself and } \\
\text { showed officers and staff a minor injury from the day before from engaging } \\
\text { in self-injurious behavior. Officers transported PS1 to the local emergency } \\
\text { room; he was held for assessment by Mobile Crisis and admitted the } \\
\text { following day to local psychiatric hospital. The administrator on duty was } \\
\text { contacted on 8-4-17 } \\
\text { at } 4: 30 \text { p.m. }\end{array}$ \\
\hline & $\begin{array}{l}\text { Sexual abuse- } \\
\text { alleged }\end{array}$ & $\begin{array}{l}\text { The program coordinator was contacted by Adult Protective Services (APS) } \\
\text { and told that PS1 alleged that staff had sexually assaulted him. APS did not } \\
\text { tell the program coordinator the date and time of this alleged incident. PS1 } \\
\text { is currently in local psychiatric hospital for treatment. No injury noted. }\end{array}$ \\
\hline & $\begin{array}{l}\text { Reportable } \\
\text { behavioral/ } \\
\text { psychiatric } \\
\text { incident- } \\
\text { other }\end{array}$ & $\begin{array}{l}\text { Staff was cleaning the living room and heard a knock on the door; officers had } \\
\text { responded to a } 911 \text { call that PS1 made saying his room was on fire. Officers } \\
\text { came in and spoke with PS1 and told him that if he continued to call } 911 \\
\text { with false reports that he could face charges. PS1 apologized and said that } \\
\text { he snuck in and got the phone while staff was in the bathroom. Officers left } \\
\text { without further intervention. No injury noted. }\end{array}$ \\
\hline & $\begin{array}{l}\text { Emotional/ } \\
\text { psychological } \\
\text { abuse- } \\
\text { alleged }\end{array}$ & $\begin{array}{l}\text { While PS1 was at the local emergency room, he would not allow staff back. } \\
\text { When he finally allowed staff to come sit with him, he told staff that his } \\
\text { home manager threatened to "whoop his ass and break his tablet" if he got } \\
\text { into any more trouble. }\end{array}$ \\
\hline PS2 & $\begin{array}{r}\text { Criminal } \\
\text { conduct }\end{array}$ & $\begin{array}{l}\text { PS2's staff called and reported that PS2 had a behavior when she was at } \\
\text { home and her mom called Mobile Crisis. PS2 was taken to the emergency } \\
\text { room; she became verbally and physically aggressive with a security guard } \\
\text { and was arrested. PS2 was later released into her mother's custody. Agency } \\
\text { staff was not present during this incident. }\end{array}$ \\
\hline PS3 & $\begin{array}{l}\text { Reportable } \\
\text { staff } \\
\text { misconduct- } \\
\text { staff } \\
\text { convenience }\end{array}$ & $\begin{array}{l}\text { During a telephone conversation with PS3's father, the father passed on } \\
\text { information told to him by his son, PS3. PS3 told his father that, on } \\
\text { 8/10/2017, he and his housemate were driven to the home of their house } \\
\text { manager, who mowed his yard while the individuals were with him. PS3 } \\
\text { played in the yard while his housemate sat in the van. As this information } \\
\text { was relayed by PS3's father, it was impossible to determine if the } \\
\text { individuals chose to travel to the house manager's home and if the } \\
\text { housemate chose to sit in the van. No injury reported. PS3 was interviewed } \\
\text { by the on-call investigator (housemate was on a home visit at the time) and } \\
\text { was capable of articulating that nothing has happened to him or to } \\
\text { housemate that has upset either of them and that they both enjoy going } \\
\text { places. PS3 confirmed that they had been taken to the staff's house but were } \\
\text { not upset or adversely affected in any way. Housemate denied being taken } \\
\text { to staff's house or being left on the van. Staff talked to PS3 and asked him } \\
\text { why he was behaving badly. Staff prompted PS3 to stop hitting himself. } \\
\text { Staff explained why PS3 shouldn't be hitting himself or hollering. Staff also } \\
\text { explained to PS3 why he shouldn't throw his books down. Staff talked to } \\
\text { PS3 and calmed him down. Physical Crisis Prevention Intervention wasn't } \\
\text { necessary. PS3 sat down and talked to staff. PS3 said he was sorry for } \\
\text { behaving the way he did. PS3 promised he wouldn't hit himself anymore. } \\
\text { PS3 went back into his room and looked at his truck books. }\end{array}$ \\
\hline
\end{tabular}




\begin{tabular}{|c|c|c|}
\hline \multicolumn{3}{|l|}{$\begin{array}{l}\text { Person } \\
\text { Support } \\
\text { (PS) }\end{array}$} \\
\hline PS3 & $\begin{array}{l}\text { Self-injurious } \\
\text { behavior }\end{array}$ & $\begin{array}{l}\text { PS3 became agitated when his truck books fell on the floor of the van from the } \\
\text { seat and got bent when the van slowed down and stopped at stop sign. PS3 } \\
\text { started hollering. He calmed down for a bit. PS3 and staff got to his } \\
\text { roommates mom's house to pick him up. His roommate did not want to go on } \\
\text { the outing and began engaging in challenging behavior, which caused PS3 } \\
\text { to get mad again, and he threw his truck book down on the ground. PS3 } \\
\text { calmed down again and he and staff got back into the van and went home. } \\
\text { On the way home in the van, PS3 seemed calm but got mad again when he } \\
\text { started looking at his bent truck book. PS3 started hollering and hitting } \\
\text { himself on the forehead, PS3 stopped hitting himself after staff prompted } \\
\text { him to stop; no injuries occurred from him doing this. PS3 and staff arrived } \\
\text { home. PS3 got out of the van and started cursing and threw his truck book } \\
\text { down on the ground again. PS3 then picked up his truck book and went into } \\
\text { his room. }\end{array}$ \\
\hline & $\begin{array}{l}\text { Self-injurious } \\
\text { behavior- } \\
\text { property } \\
\text { destruction }\end{array}$ & 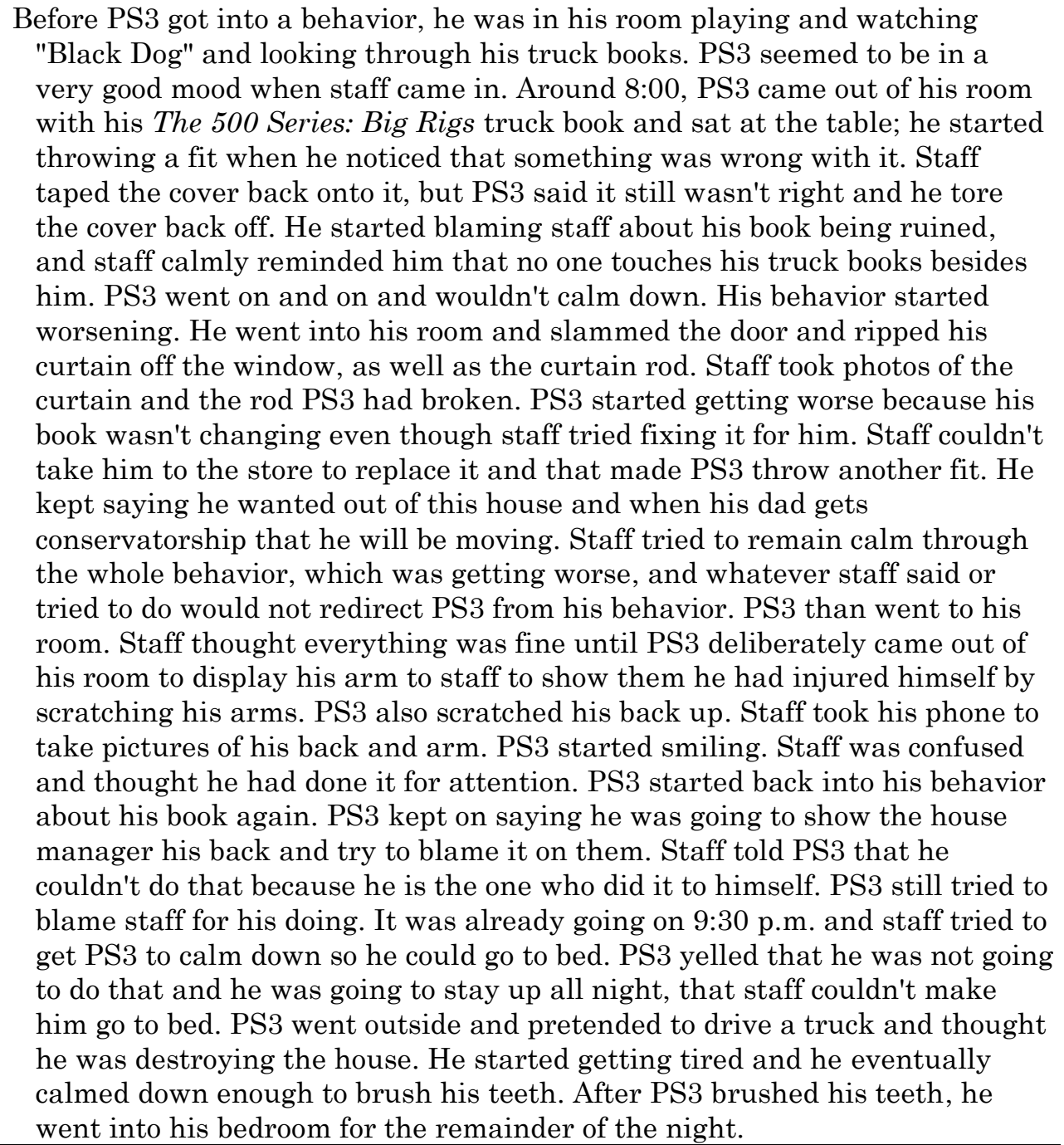 \\
\hline
\end{tabular}


Table 2. Social Validity Survey Results

\begin{tabular}{|c|c|c|c|}
\hline Question & DSP1 & DSP2 & DSP3 \\
\hline $\begin{array}{l}\text { 1. What are your } \\
\text { general thoughts } \\
\text { about using the } \\
\text { BOSS teaching } \\
\text { program in your } \\
\text { work setting? }\end{array}$ & $\begin{array}{l}\text { "I think it's great! It's a program } \\
\text { that actually produces real } \\
\text { results." }\end{array}$ & $\begin{array}{l}\text { "First will it work, and how } \\
\text { well or fast will I see } \\
\text { result from the person I'm } \\
\text { interacting with." }\end{array}$ & $\begin{array}{l}\text { "I love this program. I feel } \\
\text { this is a great way to help } \\
\text { people with mental } \\
\text { disabilities. They love to } \\
\text { know they are doing a } \\
\text { good job on the things } \\
\text { they do day to day." }\end{array}$ \\
\hline $\begin{array}{l}\text { 3. Please describe any } \\
\text { challenges, concerns, } \\
\text { or problems you may } \\
\text { have experienced } \\
\text { with implementing } \\
\text { the BOSS teaching } \\
\text { program. }\end{array}$ & $\begin{array}{l}\text { "No problems. Just making sure } \\
\text { your using positive } \\
\text { reinforcement as much as } \\
\text { possible, which in turn will } \\
\text { usually produce positive } \\
\text { behavior and can be very } \\
\text { productive for people." }\end{array}$ & $\begin{array}{l}\text { "Only problem I have is not } \\
\text { everyone is using this } \\
\text { program. I have started to } \\
\text { use it with my other } \\
\text { individual and she also } \\
\text { benefits from this } \\
\text { program. I hope one day } \\
\text { this program will be used } \\
\text { in training for all DIDD } \\
\text { programs." }\end{array}$ & $\begin{array}{l}\text { "Feeling that it won't work, } \\
\text { so why bother trying. } \\
\text { Until you actually put } \\
\text { forth effort and see great } \\
\text { results." }\end{array}$ \\
\hline
\end{tabular}

used the BOSS program with a

few clients now. I have seen a negative attitude switch to positive. I have witnessed verbal praise turn into someone's joy.

Everyone wants to feel appreciated and respected. The BOSS program teaches you how to do that no matter who you are working with. Not only have I used the BOSS program with my clients, I have used the BOSS program with my T-ball team, and with my own family. I have witnessed angry clients turn into happier clients just by giving them verbal praise, respect, and attention. The BOSS program has taught me how to be specific and intentional with my praise."
Preparation? This program whatever it is. $\mathrm{Ex}$ : $\mathrm{my}$ individual uses her manners. I thank her for using her manner and she is starting to thank program. I have started to other benefits from this program. I hope one day this program will be used in training for all DIDD programs." behavior. After using boss 


Question
5. What kinds of effects
did you notice or
observe while using
the BOSS Teaching
Program with the
individual/s you
support?

6. How likely would
you be to continue
using the BOSS
teaching program?
7. To what degree did
you notice or
observer differences
in the manner that
individual(s) you
support respond to
you or others when
you used the BOSS
teaching program?
Please explain or
describe.

Question

DSP1

"I have noticed when using the BOSS program most people respond much better with praise and respect. BOSS program teaching you how to say specific things in a very positive and effective way."

\section{“ALL THE TIME! FOREVER"}

"I have noticed a big difference in my clients, family, and my T-ball team, and at the YMCA using BOSS. Positive reinforcement brings positive changes. Praise is power."

8. What suggestions do you have for DSPs who are considering whether or not to use the BOSS teaching program?

\section{Additional/Other Comments:}

"DO IT! It really works. It works in all aspects of life."

\footnotetext{
"I feel I am a better husband to my wife because of the BOSS program. I feel I am a better father to my kids and a better coach to my T-ball team because of the BOSS program. My own personal kids have responded so much better when I'm giving positive praise and specific praise."
}

DSP2

"I have all good things to say about BOSS. The individual I support has likes to be praised for her day to day things she does. She also has started to turn her bad days around for the most, In the month we have been using BOSS."

"Extremely like. I even notice I use BOSS with another house I support that's not a part of this data collection."

"She is quicker at apologizing when she is in a behavior. BOSS tells us to focus on the good things they do and give praise statements. Also try to ignore the bad behavior. When you give less attention to the derogatory things they do it helps them realize they want to do better which results in less behavior and when they do have a behavior they will realize it and apologize quicker."

"Use it!! I works very well I even started using it with my children and have seen results."

"I feel that BOSS should be its own program and given to all Support Professionals. I think that if we use this program we will be better at supporting these individuals. They are people that just have a different way at expressing how they feel. I feel that BOSS is a great way to teach."
"No suggestions he did a great job."
"Repetition may be annoying but with the individual it helps them to hear it then practice, and make it just instinct."

"Very likely."

"Within a few days I saw a difference."
"Very thankful and pleased with the program and can't wait to see how far it goes in development and evolving to other companies in helping the individuals."

\footnotetext{
Note. DSP = direct support professional; BOSS = Behavioral Opportunities for Social Skills; DIDD $=$ Department of Intellectual and Developmental Disabilities.
} 


\section{Discussion}

The number of adults with ID who will soon be transitioning from structured institutional, school, and home environments into the regular community has been referred to as a pending crisis (BishopFitzpatrick et al., 2014; Burke et al., 2017; Cox et al., 2014; Gerhardt \& Lainer, 2011). It has been estimated that $70 \%$ of the children currently diagnosed with autism spectrum disorders alone are under the age of 14 . The large population of children currently diagnosed with ID indicates that there will be a substantial increase in the number of adults diagnosed with ID in the coming decade. However, the problem does not only pertain to the considerable increase in the number of adults diagnosed with ID, but the current lack of evidence-based interventions and supports in the community setting for these individuals. It is essential that researchers and practitioners continue to develop and expand upon the currently sparse literature of evidence-based practices for adults with ID and effective training for support staff in those practices.

The BOSS program has been shown to be effective at increasing prosocial behaviors of prekindergarten to Grade 12 students in the classroom, but this investigation represents the first application with adults with ID living in the regular community (see Long, 2016; Ross, 2015). The results of this study suggest that social skills interventions based upon the principles of ABA and developed for children can be effectively implemented with adults with ID with minimal adaptions, as previous researchers have indicated (see Ashman et al., 2018; Laugeson \& Ellingsen, 2014; Laugeson, Gantman, Kapp, Orenski, \& Ellingsen, 2015). Thus, education professionals who work with adults with ID should continue to look to the existing behavior-analytic literature for social skills interventions that have been shown to be effective with children and adolescents with ID and consider areas for potential expansion to the adult ID population.

The gap in research and practice on evidence-based social skills interventions for adults with ID is due, at least in part, to the challenges associated with delivering training and systematic evaluation of programs in the less structured community environment (Cox, Dube, \& Temple, 2014; Gantman et al., 2012; Gerhardt \& Lainer, 2011). The community setting, particularly in settings that are more rural such as where this investigation was conducted, presented logistical challenges for training DSPs in the BOSS program. To conduct the initial trainings and weekly training and feedback sessions, the sole trainer traveled nearly $90 \mathrm{mi}$. each way from an office location to the residencies of the adults with ID. It would not be practical for one trainer to provide the behavioral skills training to all DSPs across large regional areas or statewide programs.

To practically expand training opportunities for DSPs in the BOSS program, future applications could incorporate a pyramidal approach to delivering the behavioral skills training. The pyramidal approach typically includes a senior trainer (e.g., behavior analyst) directly training a small group of mid-level staff or supervisors to be approved as trainers (Andzik \& Cannella-Malone, 2017; Parsons et al., 2012). Each of the approved trainers then provides the behavioral skills training to the DSPs or other staff. Although the pyramidal approach may not reduce the overall training time for staff, it would likely reduce the training time for the senior trainer. The pyramidal training approach could exponentially expand the number of DSPs who receive training in the BOSS program by increasing the number of approved trainers. Staff maintenance of the BOSS program skills may also be enhanced when community-based agencies have multiple approved trainers working internally at the agencies.

The likelihood of staff continuing to implement a particular practice can be influenced by the staff members' acceptability of the training program (Parsons et al., 2012; Shapiro \& Kazemi, 2017). On measures of acceptability, the behavioral skills training approach has been shown to be highly acceptable to human services staff. In this investigation and in past applications of the BOSS program, teachers and staff have reported high levels of acceptability on social validity surveys (see 
Long, 2016; Ross, 2015). The training of DSPs in the highly acceptable BOSS program using a highly acceptable training approach (i.e., behavioral skills training) increases the likelihood that staff will continue to use the BOSS program on a long-term basis. However, maintenance probes were not feasible during this investigation due to time constraints. Additional research will need to be conducted to evaluate maintenance of the BOSS program implementation by support staff.

In the classroom setting, increases in the ratio of positive to negative interactions between teachers and students can lead to a more positive classroom environment (Floress et al., 2017; Stichter et al., 2009). In this investigation, the increase in DSP's delivery of BSPSs and the increases in prosocial behaviors of the adults with ID likely fostered improved relationships between the staff members and the adults with ID. Subjectively on the social validity survey, the DSPs reported that establishing a positive mindset with the BOSS program helped them to reduce negative interactions and have a positive work shift. In addition to the behavioral outcomes, the DSPs' responses on the social validity survey suggested that their adherence to the BOSS program helped foster a more positive work environment.

The potential improvements in the relationships between the DSPs and adults with ID, and the development of a more positive work environment could help reduce on-the-job stress levels of DSPs. The high stress levels of DSPs likely contribute to their high turnover rate, which has been documented to be approximately 50\% (Bogenschutz et al., 2015; Reinke et al., 2013). The high turnover rates among DSPs can be costly for community agencies who must frequently hire and retrain new DSPs who may be unhappy and highly stressed in a negative work culture. The results of this investigation suggest that incorporating the BOSS program into an agency's staff development curricula could potentially help community agencies decrease costly turnover rates by fostering a more positive work environment. Additional research will need to be conducted to evaluate potential relationships between DSP turnover rates and staff training in the BOSS program.

It is important to note that single-case research designs typically have limited generalizability due to the relatively small number of participants who tend to be included in an investigation (Kratochwill et al., 2013). This study included three different DSPs who worked with three different adults with ID, each of whom resided in different supported living residencies in the regular community.

Although the sample of the adults with ID who participated in the study had diverse intellectual and physical health diagnoses and histories of challenging behavior, the generalizability of the results of this study remain limited due to the small number of participants. The positive outcomes obtained in this study could potentially be expanded to more diverse groups of adults with ID through future direct and systematic replication studies. Additional research should focus on the inclusion of adults with ID and support staff with diverse ethnicities, adults with varied ID diagnoses, and a larger number of participants.

\section{References}

Andzik, N., \& Cannella-Malone, H. I. (2017). A review of the pyramidal training approach for practitioners working with individuals with disabilities. Behavior modification, 41, 558-580. doi: $10.1177 / 0145445517692952$

Ashman, R., Banks, K., Philip, R. C., Walley, R., \& Stanfield, A. C. (2017). A pilot randomised controlled trial of a group based social skills intervention for adults with autism spectrum disorder. Research in Autism Spectrum Disorders, 43, 67-75. doi: 10.1016/j.rasd.2017.08.001

Axelrod, S., McElrath, K. K., \& Wine, B. (2012). Applied behavior analysis: Autism and beyond. Behavioral Interventions, 27, 1-15. doi: 10.1002/bin.1335 
Bishop-Fitzpatrick, L., Minshew, N. J., \& Eack, S. M. (2014). A systematic review of psychosocial interventions for adults with autism spectrum disorders. In J. C. McPartland, B. Reichow, \& F. R. Volkmar (Eds.), Adolescents and adults with autism spectrum disorders (pp. 315-327). New York, NY: Springer.

Bogenschutz, M., Nord, D., \& Hewitt, A. (2015). Competency-based training and worker turnover in community supports for people with IDD: Results from a group randomized controlled study. Intellectual and Developmental Disabilities, 53, 182-195. doi: 10.1352/1934-955653.3.182

Burke, S. L., Wagner, E., Marolda, H., Quintana, J. E., \& Maddux, M. (2017). Gap analysis of service needs for adults with neurodevelopmental disorders. Journal of Intellectual Disabilities, 23, 97-116. doi: 10.1177/1744629517726209

Cowan, R. J., Abel, L., \& Candel, L. (2017). A meta-analysis of single-subject research on behavioral momentum to enhance success in students with autism. Journal of Autism and Developmental Disorders, 47, 1464-1477. doi: 10.1007/s10803-017-3076-6

Cox, A. D., Dube, C., \& Temple, B. (2014). The influence of staff training on challenging behaviour in individuals with intellectual disability: A review. Journal of Intellectual Disabilities, 19, 6982. doi: $10.1177 / 1744629514558075$

Delgado, C., Gonzalez-Gordon, R. G., Aragón, E., \& Navarro, J. I. (2017). Different methods for longterm systematic assessment of challenging behaviors in people with severe intellectual disability. Frontiers in Psychology, 8, 17, 1-9. doi: 10.3389/fpsyg.2017.00017

Department of Intellectual and Developmental Disabilities (DIDD). (2014). Provider manual. Retrieved from https://www.tn.gov/didd/

DiGennaro Reed, F. D., Blackman, A. L., Erath, T. G., Brand, D., \& Novak, M. D. (2018). Guidelines for using behavioral skills training to provide teacher support. Teaching Exceptional Children, 50, 373-380. doi: 10.1177/0040059918777241

Dudley, K. M., Klinger, M. R., Meyer, A., Powell, P., \& Klinger, L. G. (2019). Understanding service usage and needs for adults with ASD: The importance of living situation. Journal of Autism and Developmental Disorders, 49, 556-568. doi: 10.1007/s10803-018-3729-0

Floress, M. T., Beschta, S. L., Meyer, K. L., \& Reinke, W. M. (2017). Praise research trends and future directions: Characteristics and teacher training. Behavioral Disorders, 43, 227-243. doi: $10.1177 / 0198742917704648$

Friedman, C. (2018). Direct support professionals and quality of life of people with intellectual and developmental disabilities. Intellectual and Developmental Disabilities, 56, 234-250. doi: 10.1352/1934-9556-56.5.234

Gantman, A., Kapp, S. K., Orenski, K., \& Laugeson, E. A. (2012). Social skills training for young adults with high-functioning autism spectrum disorders: A randomized controlled pilot study. Journal of Autism and Developmental Disorders, 42, 1094-1103. doi: 10.3102/0034654317740334

Gerhardt, P. F., \& Lainer, I. (2011). Addressing the needs of adolescents and adults with autism: A crisis on the horizon. Journal of Contemporary Psychotherapy, 41, 37-45. doi: 10.1177/070674371205700503

Hassan, M., Simpson, A., Danaher, K., Haesen, J., Makela, T., \& Thomson, K. (2018). An evaluation of behavioral skills training for teaching caregivers how to support social skill development in their child with autism spectrum disorder. Journal of Autism and Developmental Disorders, 48, 1957-1970. doi: 10.1007/s10803-017-3455-z 
Heyman, M., Stokes, J. E., \& Siperstein, G. N. (2016). Not all jobs are the same: Predictors of job quality for adults with intellectual disabilities. Journal of Vocational Rehabilitation, 44, 299-306. doi: 10.3233/JVR-160800

Hotton, M., \& Coles, S. (2016). The effectiveness of social skills training groups for individuals with autism spectrum disorder. Review Journal of Autism and Developmental Disorders, 3, 68-81. doi: 10.1007/s40489-015-0066-5

Jenkins, L. N., Floress, M. T., \& Reinke, W. (2015). Rates and types of teacher praise: A review and future directions. Psychology in the Schools,52, 463-476. doi: 10.1002/pits.21835

Ke, F., Whalon, K., \& Yun, J. (2018). Social skill interventions for youth and adults with autism spectrum disorder: A systematic review. Review of Educational Research, 88, 3-42. doi: $10.3102 / 0034654317740334$

Kearney, D. S., \& Healy, O. (2011). Investigating the relationship between challenging behavior, comorbid psychopathology and social skills in adults with moderate to severe intellectual disabilities in Ireland. Research in Developmental Disabilities, 32, 1556-1563. doi: 10.1016/j.ridd.2011.01.053

Koegel, L. K., Ashbaugh, K., Koegel, R. L., Detar, W. J., \& Regester, A. (2013). Increasing socialization in adults with Asperger's syndrome. Psychology in the Schools, 50, 899-909. doi: 10.1002/pits.21715

Kratochwill, T. R., Hitchcock, J. H., Horner, R. H., Levin, J. R., Odom, S. L., Rindskopf, D. M., \& Shadish, W. R. (2013). Single-case intervention research design standards. Remedial and Special Education, 34, 26-38. doi: 10.1177/0741932512452794

Laugeson, E. A., \& Ellingsen, R. (2014). Social skills training for adolescents and adults with autism spectrum disorder. In J. C. McPartland, B. Reichow, \& F. R. Volkmar (Eds.), Adolescents and adults with autism spectrum disorders (pp. 61-85). New York, NY: Springer.

Laugeson, E. A., Gantman, A., Kapp, S. K., Orenski, K., \& Ellingsen, R. (2015). A randomized controlled trial to improve social skills in young adults with autism spectrum disorder: The UCLA PEERS Program. Journal of Autism and Developmental Disorders, 45, 3978-3989. doi: $10.1007 / \mathrm{s} 10803-015-2504-8$

Lerner, J. G., \& Pollack, D. (2015). Where have all the developmental centers gone? The federal push for community-based services for people with intellectual and developmental disabilities. Capital University Law Review, 43, 751-776. Retrieved from https://www.newyorkpersonalinjuryattorneysblog.com/files/2016/01/Where-have-all-thedevelopmental-centers-gone-1-12-16-1.pdf

Lloyd, B. P., \& Kennedy, C. H. (2014). Assessment and treatment of challenging behaviour for individuals with intellectual disability: A research review. Journal of Applied Research in Intellectual Disabilities, 27, 187-199. doi: 10.1111/jar.12089

Long, A. L. (2016). Reculturing and rebuilding learning communities through responsive classroom management practices (Doctoral dissertation). Tift College of Education, Mercer University, Atlanta, GA. doi: 10/10/10103708

Matson, J. L., \& Adams, H. L. (2014). Characteristics of aggression among persons with autism spectrum disorders. Research in Autism Spectrum Disorders, 8, 1578-1584. doi: 10.1016/j.rasd.2014.08.004

Matson, J. L., Cervantes, P. E., \& Peters, W. J. (2016). Autism spectrum disorders: Management over the lifespan. Expert Review of Neurotherapeutics, 16, 1301-1310. doi: 10.1080/14737175.2016.1203255 
Matson, J. L., Hattier, M. A., \& Turygin, N. (2012). An evaluation of social skills in adults with pica, autism spectrum disorders, and intellectual disability. Journal of Developmental and Physical Disabilities, 24, 505-514. doi: 10.1007/s10882-012-9286-0

Matson, J. L., Turygin, N. C., Beighley, J., Rieske, R., Tureck, K., \& Matson, M. L. (2012). Applied behavior analysis in autism spectrum disorders: Recent developments, strengths, and pitfalls. Research in Autism Spectrum Disorders, 6, 144-150. doi: 10.1016/j.rasd.2011.03.014

Mrachko, A. A., Kostewicz, D. E., \& Martin, W. P. (2017). Increasing positive and decreasing negative teacher responses to student behavior through training and feedback. Behavior Analysis: Research and Practice, 17, 250-265. doi: 10.1037/bar0000082

Parsons, M. B., Rollyson, J. H., \& Reid, D. H. (2012). Evidence-based staff training: A guide for practitioners. Behavior Analysis in Practice, 5, 2-11. doi: 10.1007/BF03391819

Partin, T. M., Robertson, R. E., Maggin, D. M., Oliver, R. M., \& Wehby, J. H. (2010). Using teacher praise and opportunities to respond to promote appropriate student behavior. Preventing School Failure, 54, 172-178. doi: 10.1080/10459880903493179

Ratto, A. B., \& Mesibov, G. B. (2015). Autism spectrum disorders in adolescence and adulthood: Long-term outcomes and relevant issues for treatment and research. Science China Life Sciences, 58, 1010-1015. doi: 10.1007/s11427-012-4295-x

Ross, P. (2015). Evidence-based practices for BOSS. Saarbrucken, Germany: Lap Lambert.

Ross, P. \& Sliger, B. (2015). The current state of evidence-based practices with classroom management. National Social Science Journal, 43, 76-80.

Shapiro, M., \& Kazemi, E. (2017). A review of training strategies to teach individuals implementation of behavioral interventions. Journal of Organizational Behavior Management, 37, 32-62. doi: 10.1080/01608061.2016.1267066

Simonsen, B., Fairbanks, S., Briesch, A., Myers, D., \& Sugai, G. (2008). Evidence-based practices in classroom management: Considerations for research to practice. Education and Treatment of Children, 351-380. doi: 10.1353/etc.0.0007

Simonsen, B., Freeman, J., Dooley, K., Maddock, E., Kern, L., \& Myers, D. (2017). Effects of targeted professional development on teachers' specific praise rates. Journal of Positive Behavior Interventions, 19, 37-47. doi: 10.1177/1098300716637192

Stichter, J. P., Lewis, T. J., Whittaker, T. A., Richter, M., Johnson, N. W., \& Trussell, R. P. (2009). Assessing teacher use of opportunities to respond and effective classroom management strategies: Comparisons among high-and low-risk elementary schools. Journal of Positive Behavior Interventions, 11, 68-81. doi: 10.1177/1098300708326597

Turcotte, P., Mathew, M., Shea, L. L., Brusilovskiy, E., \& Nonnemacher, S. L. (2016). Service needs across the lifespan for individuals with autism. Journal of Autism and Developmental Disorders, 46, 2480-2489. doi: 10.1007/s10803-016-2787-4

Vannest, K. J., \& Ninci, J. (2015). Evaluating intervention effects in single-case research designs. Journal of Counseling \& Development, 93, 403-411. doi: 10.1002/jcad.12038

Walsh, L., Lydon, S., \& Healy, O. (2014). Employment and vocational skills among individuals with autism spectrum disorder: Predictors, impact, and interventions. Review Journal of Autism and Developmental Disorders, 1, 266-275. doi: 10.1007/s40489-014-0024-7

Walton, K. M., \& Ingersoll, B. R. (2013). Improving social skills in adolescents and adults with autism and severe to profound intellectual disability: A review of the literature. Journal of Autism and Developmental Disorders, 43, 594-615. doi: 10.1007/s10803-012-1601-1 
Wong, C., Odom, S. L., Hume, K. A., Cox, A. W., Fettig, A., Kucharczyk, S., . . Schultz, T. R. (2015). Evidence-based practices for children, youth, and young adults with autism spectrum disorder: A comprehensive review. Journal of Autism and Developmental Disorders, 45, 1951-1966. doi: 10.1007/s10803-014-2351-z

The Journal of Educational Research and Practice provides a forum for studies and dialogue that allows readers to better develop social change in the field of education and learning. Journal content may focus on educational issues of all ages and in all settings. It also presents peer-reviewed commentaries, book reviews, interviews of prominent individuals, and additional content. The objectives: We publish research and related content that examines current relevant educational issues and processes aimed at presenting readers with knowledge and showing how that knowledge can be used to impact social change in educational or learning environments. Additional content provides an opportunity for scholarly and professional dialogue regarding that content's usefulness in expanding the body of scholarly knowledge and increasing readers' effectiveness as educators. The journal also focuses on facilitating the activities of both researcher-practitioners and practitioner-researchers, providing optimal opportunities for interdisciplinary and collaborative thought through blogging and other communications.

Walden University Publishing: http://www.publishing.waldenu.edu 